DOI: 10.12731/2658-6649-2021-13-3-193-207

УДК 57.048

\title{
ОСОБЕННОСТИ \\ СОЦИАЛЬНО-ПСИХОЛОГИЧЕСКОЙ \\ И ФИЗИОЛОГИЧЕСКОЙ АДАПТАЦИИ КУРСАНТОВ \\ ВУЗА МВД К УСЛОВИЯМ СЛУЖЕБНОЙ ДЕЯТЕЛЬНОСТИ
}

\author{
Л.Е. Дерягина, С.В. Булатецкий
}

Неоднозначность процесса профессиональной адаптачии вызывает постоянный интерес исследователей. Целью нашей работы было выявление особенностей физиологической и соииально-психологической адаптации курсантов к условиям служебной деятельности.

Материалы и методы. В исследовании принимали участие курсанты факультета психологии Московского университета МВД РФ им.В.Я. Кикотя в количестве 30 человек (7 юношей и 23 девушки) в возрасте от 18 до 22 лет. Уровень соииально-психологической адаптации определяли по методике диагностики Роджерса-Даймонд, вегетативную регуляиию ритма сердиа оченивали по параметрам вариабельности ритма сердиа (ВРC) по методике Р.М. Баевского согласно Евро-Американским рекомендациям. Исследование ВРС проводили дважды, до заступления в суточный наряд и после его окончания.

Результаты. Все испытуемые разделились на 3 группы по уровню адаптированности от низкого до высокого (НУ, СУ, ВУ). Умеренное преобладание симпатических влияний перед заступлением в наряд сменялось нарастанием вклада парасимпатической системь в регуляцию ритма сердия после наряда в группах НУ и СУ. В группе ВУ до наряда преобладала активачия парасимпатического отдела нервной системы. После наряда наблюдался эутонический тип регулящии.

Выводы. 1. Уровень сочиально-психологической адаптации курсантов взаимосвязан с паттерном вегетативной регуляции ритма сердиа в ситуачии суточного наряда. 2. У лии с высоким уровнем адаптивности сформирована относительно автономная система регуляиии ритма сердиа, которая в силу независимости ее элементов отличается большей пластичностью, что облегчает ее приспособление к изменяющимся условиям среды, включая, приспособление к условиям служебной деятельности. 
Ключевые слова: профессия; адаптация; сочиально-психологическая; физиологическая; вариабельность ритма сердиа

Для цитирования. Дерягина Л.Е., Булатеикий С.В. Особенности соииально-психологической и физиологической адаптачии курсантов вуза МВД кусловиям служебной деятельности // Siberian Journal of Life Sciences and Agriculture. 2021. T. 13, № 3. C. 193-207. DOI: 10.12731/2658-6649-2021-13-3-193-207

\section{FEATURES OF SOCIO-PSYCHOLOGICAL AND PHYSIOLOGICAL ADAPTATION OF CADETS OF THE UNIVERSITY OF THE MINISTRY OF INTERNAL AFFAIRS TO THE CONDITIONS OF SERVICE ACTIVITY}

\section{L.E. Deryagina, S.V. Bulatetskiy}

Background. The ambiguity of the professional adaptation process is of constant interest to researchers.

Purpose. The purpose of our work was to identify the features of physiological and socio-psychological adaptation of cadets to the conditions of service.

Materials and methods. The study involved cadets of the Faculty of Psychology of the Vladimir Kikot Moscow University of the Ministry of Internal Affairs of Russia in the amount of 30 people ( 7 men and 23 women) aged 18 to 22 years. The level of socio-psychological adaptation was determined according to the Rogers-Diamond diagnostic method, the autonomic regulation of the heart rate was assessed by the parameters of the heart rate variability (HRV) according to the method of R.M. Baevsky and Euro-American recommendations. The HRV study was carried out twice: before entering the 24-hour duty and after its completion.

Results: all subjects were divided into 3 groups according to the level of adaptation from low to high (LA, MA, HA). Moderate predominance of sympathetic influences before going to the duty was taking turn by the growth of the contribution of the parasympathetic system in the regulation of heart rate after the duty in the LA and MA groups. In the HA group before the duty, prevailed activation of the parasympathetic division of the nervous system. After the duty, an eutonic type of regulation was observed.

Conclusions. 1. The level of socio-psychological adaptation of cadets is interrelated with the pattern of vegetative regulation of the heart rate in the conditions of 24-hour duty. 2. Persons with a high level of adaptability have formed a 
relatively autonomous system of regulation of the heart rhythm, which, due to the independence of its elements, is distinguished by greater plasticity, which facilitates its adaptation to changing environmental conditions, including adaptation to the conditions of service activity.

Keywords: profession; adaptation; socio-psychological; physiological; heart rate variability

For citation. Deryagina L.E., Bulatetskiy S.V. Features of socio-psychological and physiological adaptation of cadets of the university of the Ministry of Internal Affairs to the conditions of service activity. Siberian Journal of Life Sciences and Agriculture, 2021, vol. 13, no. 3, pp. 193-207. DOI: 10.12731/2658-6649-2021-13-3-193-207

Профессиональная адаптация - сложный многокомпонентный процесс, включающий несколько аспектов: психологический, социологический, физиологический. Этимологически понятие «адаптация» происходит от латинского «adaptio» - приспособление. В широком смысле адаптация трактуется как приспособление организма к изменяющимся внешним условиям. Первоначальная трактовка адаптации как биологического процесса претерпела значительные изменения. Традиционно рассматриваются два фундаментальных уровня адаптации: физиологический и социально-психологический. Первый - физиологический - подразумевает приспособительные реакции регуляторных и исполнительных механизмов организма для поддержания гомеостатического равновесия внутренней среды. Второй - социально-психологический - определяется как процесс приобретения людьми определенного социально-психологического статуса, овладения теми или иными социально-психологическими функциями. Процесс адаптации чрезвычайно динамичен, его успешность зависит от функционального состояния, социального опыта, индивидуальных особенностей личности [11]. В процессе адаптации к службе в органах внутренних дел выделяются следующие структурные элементы: к профессии, к учреждению (органу, подразделению) и социально-бытовую адаптацию, в каждом из которых присутствуют предметный и социально-психологический аспекты $[7,17]$. Курсанты вузов МВД представляют особую группу обучающихся, одновременно совмещающих учебную и служебную деятельность, при этом прослеживаются все вышеназванные структурные элементы адаптации. К специфичным условиям жизнедеятельности курсантов можно отнести: регламентированные условия быта и распорядка дня; ограничения в средствах реализации актуальных потребностей; жесткая регламентация и субординация общения с руково- 
дителями и внутригруппового общения; появление новых обязанностей по несению суточных нарядов, дежурств, служб и так далее [9]. Это необходимо для подготовки курсантов к будущей сложной профессиональной деятельности $[14,17]$.

Не вызывает сомнения, что социально-психологическая составляющая процесса адаптации крайне важна в процессе приспособления к профессиональным особенностям любой деятельности [6]. Эти адаптивные процессы проявляются наиболее выпукло, во многих вузах вводится психологическое сопровождение деятельности [2]. Вместе с тем, физиологическая составляющая - «цена адаптации», нередко игнорируется, подменяясь констатацией заболеваемости. Исходя из теории стресса Г.Селье, к заболеваниям приводят сверхсильные и длительно действующие факторы среды. В то же время, реакция на однотипные средовые факторы отличается у лиц с различной резистентностью. Следовательно, изолированное изучение разных сторон процесса адаптации не может в полной мере отражать весь многогранный спектр приспособительных реакций. В связи с этим, комплексное изучение адаптационных процессов вызывает несомненный научный интерес.

Целью нашей работы было выявление особенностей социально-психологической и физиологической адаптации курсантов к условиям служебной деятельности.

\section{Материалы и методы}

В исследовании принимали участие курсанты факультета психологии Московского университета МВД РФ им.В.Я.Кикотя в количестве 30 человек (7 юношей и 23 девушки) в возрасте от 18 до 22 лет с 1 по 4 курсы. От всех участников исследования было получено информированное согласие. Проводился анализ успеваемости, количества поощрений и случаев заболеваний с временной утратой трудоспособности. Использовалась методика диагностики социально-психологической адаптации Роджерса-Даймонд, которая предназначена для выявления психологических реакций, сопровождающих процесс социально-психологической адаптации и иные ее показатели, такие как адаптация, интернальность, принятие других, самопринятие, эмоциональная комфортность и стремление к доминированию [12]. Вегетативную регуляцию оценивали по параметрам вариабельности ритма сердца (ВРС) по методике Р.М. Баевского, использовали устройство психофизиологического тестирования «Психофизиолог - УПФТ-1/30 (Медиком МТД - Таганрог, Россия) $[1,8,18,20]$. 
Регистрировали электрокардиограмму (ЭКГ) во втором стандартном отведении в положении сидя в режиме ВКМ-128 (128 кардиинтервалов) в 2 этапа: до заступления в суточный наряд и после его окончания. Оценивали показатели статистического анализа: стандартное отклонение интервала RR (CКО, мс); моду - Мо(c), амплитуду моды - Амо(\%), вариационный размах - ВР, индекс напряжения регуляторных систем (ИН). При спектральном анализе определяли значения мощностей высокочастотных (HighFrequency - HF, дыхательные волны) 0,4-0,15 Гц(2,5-6,5 сек.), низкочастотных (LowFrequency - LF, медленные волны 1-го порядка) 0,15-0,04 Гц(6,5-25 сек.), диапазонов согласно Евро-Американским рекомендациям [3]. По данным спектрального анализа сердечного ритма вычисляли индекс вагосимпатического взаимодействия LF/HF.

Статистическую обработку данных проводили с помощью программы «Statistic for Windows», версия 10.0. Нормальность распределения проверяли по тесту Shapiro-Wilk для малых выборок. Распределение практически всех показателей отличалось от нормального, для сравнения групп использовались методы непараметрической статистики (для сравнения межгрупповых данных использовался критерий Манн-Уитни для независимых выборок). Для описаний показателей в группах в качестве характеристик положения и рассеяния использовались медиана и квартили (25 и $75 \%$ ). Выявление взаимосвязи показателей проводилось с помощью рангового корреляционного анализа r-Спирмена. Критический уровень значимости (р) принимался равным 0,05 .

\section{Результаты}

Для анализа полученных результатов курсанты были разделены на 3 группы в зависимости от успешности учебной и служебной деятельности (рис.1), как объективных индикаторов процесса адаптации. Успешность учебной деятельности оценивали по среднему баллу успеваемости, служебной - по количеству поощрений. Кроме того, рассчитывали количество случаев заболеваний, повлекших временную нетрудоспособность. Данные параметры оценивались за весь период учебы в вузе.

Курсанты 1-й группы имели значения выше, чем во 2-й и 3-й группах по шкалам: дезадаптивность, непринятие себя и других, эмоциональный дискомфорт, внешний контроль, ведомость, однако все параметры находились в пределах нормы по интерпретации методики. Эмоциональный комфорт, принятие себя и адаптивность в этой группе были статистически значимо ниже по сравнению со 2 и 3 группами. 


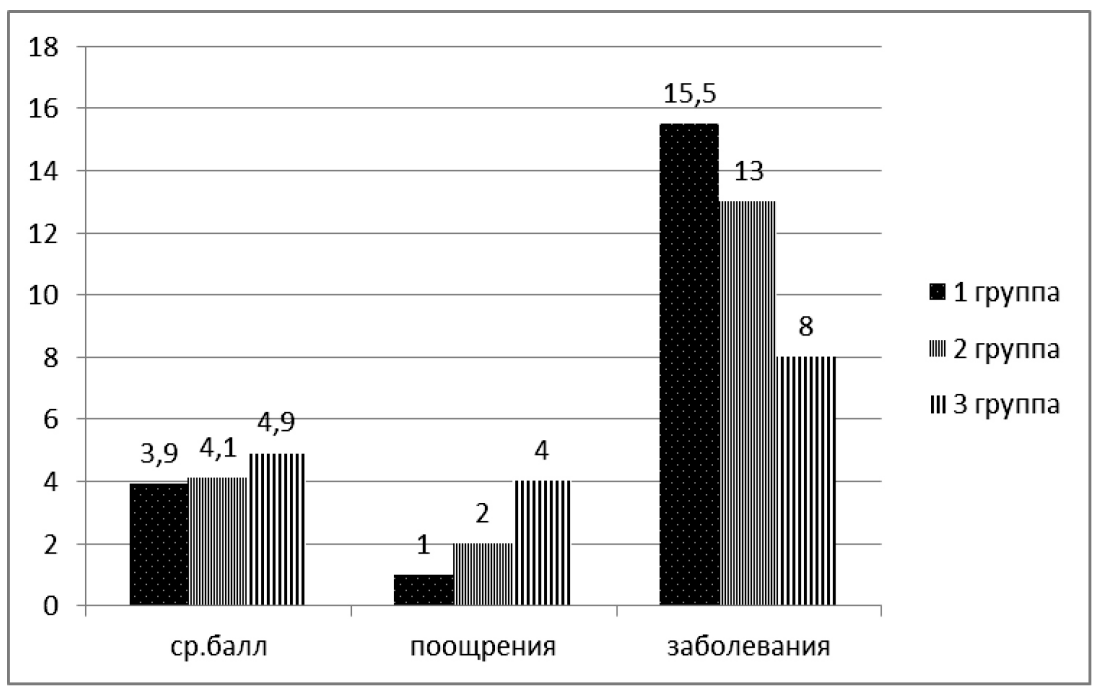

Рис. 1. Распределение на группы

Таблиияа 1.

Параметры социально-психологической адаптации (Me, $\left.\mathrm{C}_{25}-\mathrm{C}_{75}\right)$

\begin{tabular}{|l|c|c|c|c|}
\hline \multicolumn{1}{|c|}{ Характеристики } & $\mathbf{1}$ групп (n=8) & $\begin{array}{c}\mathbf{2} \text { группа } \\
(\mathbf{n = 1 3 )}\end{array}$ & $\begin{array}{c}\mathbf{3} \text { группа } \\
(\mathbf{n = 9 )}\end{array}$ & $\mathbf{p}$ \\
\hline Адаптивность & $133,5(112 ; 153)$ & $149,5(142 ; 158)$ & $154(149 ; 156)$ & $0,013^{1-2,3}$ \\
\hline Дезадаптивность & $78(45 ; 90)$ & $68,5(45 ; 99)$ & $72(71 ; 74)$ & \\
\hline Принятия себя & $38,5(31 ; 48)$ & $50,5(44 ; 54)$ & $50(45 ; 50)$ & $0,014^{1-2,3}$ \\
\hline Непринятия себя & $14(13 ; 16)$ & $13(6 ; 15)$ & $10(8 ; 11)$ & \\
\hline Принятие других & $25,5(19 ; 27)$ & $26,5(23,5 ; 28,5)$ & $27(26 ; 27)$ & \\
\hline Непринятие других & $16(11: 16)$ & $15(11 ; 22,5)$ & $13(14 ; 16)$ & \\
\hline $\begin{array}{l}\text { Эмоциональный } \\
\text { комфорт }\end{array}$ & $24,5(24 ; 27)$ & $27,5(23,5 ; 31,5)$ & $30(26 ; 30)$ & \\
\hline $\begin{array}{l}\text { Эмоциональный } \\
\text { дискомфорт }\end{array}$ & $13(13 ; 16)$ & $11,5(7 ; 22)$ & $10(5 ; 17)$ & $0,040^{1-2,3}$ \\
\hline Внутренний контроль & $55,5(46 ; 59)$ & $64(61 ; 66,5)$ & $65(58 ; 68)$ & \\
\hline Внешний контроль & $20(6 ; 18)$ & $16,5(5,5 ; 25,5)$ & $17(16 ; 22)$ & \\
\hline Доминирование & $5,8(5 ; 11)$ & $10(8,5 ; 11)$ & $13(11 ; 13)$ & \\
\hline Ведомость & $15(15 ; 16)$ & $13,5(5 ; 17)$ & $10(13 ; 18)$ & \\
\hline Эскапизм & $13(10 ; 14)$ & $15(12 ; 15,5)$ & $13(13 ; 16)$ & \\
\hline Искренность & $27,5(21 ; 33)$ & $29(26,5 ; 32,5)$ & $22(17 ; 27)$ & \\
\hline
\end{tabular}


Курсанты 3-й группы имели диаметрально противоположные параметры социально-психологической адаптации. Курсанты 2-й группы занимали промежуточное положение по данным показателям. Таким образом, анализ параметров социально-психологической адаптации показал более низкий ее уровень в 1-й группе наименее успешных курсантов.

Помимо социально-психологической адаптации к служебной деятельности нами также была изучена ментальная адаптация, изучение которой проводили при помощи анализа вариабельности ритма сердца (ВРС). Ритм сердца является общепризнанным индикатором средовых влияний на организм. Суточные наряды являются обязательными составляющими служебной деятельности курсантов, наиболее приближенными к реальным условиям службы. Измерение параметров вегетативной регуляции производилось до заступления в наряд в дневные часы и после окончания наряда в вечерние часы.

Таблица 2.

Параметры вариабельности ритма сердца до суточного наряда $\left(\mathrm{Me}, \mathrm{C}_{25}-\mathrm{C}_{75}\right)$

\begin{tabular}{|l|c|c|c|c|}
\hline & 1 групп (n=8) & $\mathbf{2}$ группа (n=13) & $\mathbf{3}$ группа (n=9) & p \\
\hline СКО & $69(62 ; 78)$ & $50,5(36 ; 58)$ & $78(36 ; 141)$ & $0,038^{1-2}$ \\
\hline Mо & $725(625 ; 725)$ & $700(650 ; 750)$ & $825(725 ; 825)$ & \\
\hline Амо & $37,3(33,8 ; 38,6)$ & $35,8(31,3 ; 44,1)$ & $26,2(24,2 ; 53,5)$ & \\
\hline BР & $394,5(297 ; 422)$ & $230(171,5 ; 261)$ & $409(311 ; 705)$ & $0,009^{1-2}$ \\
\hline ИН & $68,1(56,1 ; 75,7)$ & $108,5(79,0 ; 116,8)$ & $31,8(18,5 ; 73,3)$ & $0,030^{1-2}$ \\
\hline LF & $53,9(29,1 ; 81,9)$ & $54,8(28,2 ; 82,7)$ & $39,2(35,3 ; 64,6)$ & \\
\hline HF & $46,1(18,0 ; 70,9)$ & $45,2(17,3 ; 71,8)$ & $60,8(35,4 ; 64,7)$ & \\
\hline LF/HF & $1,26(0,52 ; 3,03)$ & $1,31(0,4 ; 6,1)$ & $0,6(0,5 ; 1,8)$ & $0,040^{1-2}$ \\
\hline IC & $1,82(0,71 ; 8,05)$ & $3,5(0,9 ; 8,3)$ & $1,3(0,7 ; 2,3)$ & \\
\hline
\end{tabular}

Следует сразу оговориться, что все полученные результаты вариабельности ритма сердца находились в пределах рекомендованных нормативных значений. Соответственно, анализ полученных данных строился на сравнении между выделенными группами курсантов.

Представленные в таблицах 2 и 3 данные иллюстрируют однотипность изменений параметров ВРС в 1 и 2 группах до и после суточного наряда. Умеренное преобладание симпатических влияний перед заступлением в наряд сменялось нарастанием вклада парасимпатической системы в регуляцию ритма сердца после наряда. При этом следует отметить, что у курсантов 2-й группы вклад симпатической системы был более выражен (СКО, ВР, ИН). 
Таблицча 3.

Параметры вариабельности ритма сердца после суточного наряда

\begin{tabular}{|l|c|c|c|c|}
\hline & 1 групп (n=8) & $\mathbf{2}$ группа (n=13) & 3 группа (n=9) & p \\
\hline СКО & $102(85 ; 109)$ & $77(66,5 ; 97,5)$ & $137(64 ; 147)$ & $0,026^{1-2}$ \\
\hline Mо & $925(825 ; 975)$ & $825(800 ; 875)$ & $925(725 ; 975)$ & \\
\hline Амо & $26,4(23,6 ; 27,6)$ & $28,9(24,4 ; 35,9)$ & $26,4(20 ; 32,3)$ & \\
\hline BP & $597,5(384 ; 682)$ & $494,5(372 ; 620,5)$ & $728(484 ; 756)$ & \\
\hline ИH & $27,4(17,8 ; 36,7)$ & $43,4(22,7 ; 60,9)$ & $15,5(14,2 ; 61,6)$ & $0,026^{1-2}$ \\
\hline LF & $41,7(40,2 ; 43,0)$ & $40,3(35,4 ; 42,8)$ & $44,6(34,3 ; 59,3)$ & \\
\hline HF & $58,3(56,9 ; 59,7)$ & $59,7(57,2 ; 64,6)$ & $55,4(40,7 ; 65,7)$ & \\
\hline LF/HF & $0,71(0,67 ; 0,75)$ & $0,6(0,5 ; 0,7)$ & $0,8(0,5 ; 1,5)$ & \\
\hline IC & $1,2(0,8 ; 1,7)$ & $0,9(0,9 ; 1,1)$ & $1,3(1,0 ; 2,2)$ & \\
\hline
\end{tabular}

Совершенно иная картина наблюдалась в 3-й группе курсантов. Перед заступлением в наряд преобладала активация парасимпатического отдела нервной системы, что иллюстрируется индексом вагосимпатического взаимодействия LF/HF и нормализованными индексами LF и HF (табл. 2). После наряда наблюдается практически эутоническая реакция на нагрузку за счет активации симпатического отдела и снижения активности парасимпатического (табл. 3).

Проведенный корреляционный анализ выявил статистически значимые связи $(\mathrm{p}<0,05)$ между параметрами социально-психологической адаптации и вариабельности ритма сердца. Так, показатели «принятие других» и «эмоциональный комфорт» были отрицательно связаны с показателями ВРС, отражающими вклад симпатической системы (Амо $(\mathrm{r}=-0.56, \mathrm{r}=-0.53), \mathrm{LF}(\mathrm{r}=-0,61, \mathrm{r}=-0,56), \mathrm{LF} / \mathrm{HF}(\mathrm{r}=-0,60, \mathrm{r}=-0,56))$ и положительно - с нормализованным индексом дыхательных волн (НF $(\mathrm{r}=0,61, \mathrm{r}=0,56)$, отражающим вклад парасимпатической системы. Напротив, параметр «эмоциональный дискомфорт» имел прямо противоположные связи с параметрами ВРС (Амо (r=0,61), LF(r=0,52), LF/HF $(\mathrm{r}=0,52)$, HF $(\mathrm{r}=-0,52))$. Выявленные закономерности указывают на то, что позитивные тенденции социально-психологической адаптации сопровождаются эутонической, наиболее гармоничной регуляцией ритма сердца.

\section{Обсуждение результатов}

Полученные в нашем исследовании данные не противоречат основным постулатам теории адаптации. Воздействие однотипных средовых факто- 
ров (внешних) вызывает дифференцированные реакции у лиц с различным уровнем адаптационной способности (внутренних) [13]. Под адаптационной способностью понимают способность человека приспосабливаться к различным условиям среды без ощущения внутреннего дискомфорта и без конфликта со средой [4]. Курсантам 1-й группы с более низким уровнем адаптивности свойственна неуверенность в принятии решения, сложность в достижении поставленной цели при возникновении трудностей. Самооценка неустойчивая, зависит от ситуации успеха или неудачи, однако в целом курсанты первой группы удовлетворены своими личностными качествами.

Курсантам второй группы со средним уровнем адаптивности характерно адекватное восприятие себя и своей деятельности, адекватная самооценка. Проявляется стремление к установлению социальных контактов и совместному решению поставленных задач. Курсанты, в основном, уверены в своих силах, настойчивы в достижении целей, испытывают лидерские притязания.

Для курсантов третьей группы с высоким уровнем адаптивности характерна адекватная самооценка, удовлетворенность своей деятельностью и высокий уровень достижения цели. Характерно стремление к взаимодействию с окружающими, совместной деятельности.

В нашем исследовании физиологическая составляющая процесса адаптации оценивалась по параметрам вариабельности ритма сердца, как универсального индикатора средовых влияний, чутко откликающегося на все внешние и внутренние возмущающие факторы [8]. Полученные результаты указывают на дифференцированное реагирование на ситуацию суточного наряда в зависимости от уровня адаптивности. Более энергетически затратные процессы (активация симпатического отдела) наблюдались перед заступлением в наряд у курсантов 2-й группы со средним уровнем адаптивности, что, вероятно связано с осознанием ответственности с одной стороны, и адекватной оценкой недостаточных собственных возможностей с другой стороны. В группе с низким уровнем адаптации более умеренная активация симпатического отдела свидетельствует о сниженной социальной ответственности, что проявляется в меньшей успешности учебной и служебной деятельности. Для этой группы также характерен более высокий уровень внешнего контроля. В группе с самым высоким уровнем адаптивности диаметрально противоположный паттерн регуляции на этапе заступления в наряд (более высокая активность парасимпатического отдела) указывает на имеющи- 
еся функциональные резервы организма и менее затратные механизмы регуляции деятельности. Наиболее близко к исследованиям экстремальной профессиональной деятельности находятся исследования в спорте. Одним из физиологических механизмов оптимального приспособления организма к условиям спортивной деятельности является снижение степени функционального напряжения регуляторных механизмов организма, их переход на более экономичный тип работы в покое и в подготовительный период тренировочного цикла [5].

Таким образом, наши данные о более экономном паттерне регуляции в группе курсантов с высоким уровнем адаптивности согласуются с результатами успешных спортсменов. Ситуация суточного наряда в нашем исследовании является комплексной экспериментальной средой, в которой проявляются нарушение привычных циркадианных суточных ритмов [16], необходимость неукоснительного выполнения служебных обязанностей, длительное напряжение опорно-двигательного аппарата и т.д. Проблема напряжения и перенапряжения физиологических систем организма при воздействии средовых факторов особенно актуальна в условиях значительного роста социально-стрессовых ситуаций, что характерно для нашего времени [10]. Готовность выполнять служебные обязанности сопровождается дифференцированным изменением функционального состояния организма курсантов в зависимости от уровня адаптивности $[15,19]$, что необходимо учитывать при организации деятельности и проведении коррекционных мероприятий с группой лиц, имеющей более низкий уровень социально-психологической адаптации.

\section{Выводы:}

1. Уровень социально-психологической адаптации курсантов взаимосвязан с паттерном вегетативной регуляции ритма сердца в ситуации суточного наряда.

2. У лиц с высоким уровнем адаптивности сформирована относительно автономная система регуляции ритма сердца, которая в силу независимости ее элементов отличается большей пластичностью, что облегчает ее приспособление к изменяющимся условиям среды, включая, приспособление к условиям служебной деятельности.

Информация о конфликте интересов. Авторы заявляют об отсутствии конфликта интересов. 


\section{Сиисок литературы}

1. Анализ вариабельности сердечного ритма при использовании различных электрокардиографических систем. Часть 1 / Р.М. Баевский, Г.Г. Иванов, Л.В. Чирейкин и др. // Вестник аритмологии. 2001. № 24. С. 65-86. http:// www.vestar.ru/atts/1267/24baevsky.pdf

2. Бочарская И.А. Профессиональная и социально-психологическая адаптация студентов в вузе как процесс воспитания социально-ориентированной и конкурентноспособной личности // Вестник Казанского государственного университета культуры и искусств. 2006. № 3. С. 125-127.

3. Вариабельность сердечного ритма. Стандарты измерения, физиологической интерпретации и клинического использования / Рабочая группа Европейского кардиологического общества и Северо-Американского обществ стимуляции и электрофизиологии // Вестник аритмологии. 1999. № 11. С. 53-78. http://www.vestar.ru/atts/2581/258101.pdf

4. Васильева И.А. Особенности социально-психологической адаптации сотрудников спецподразделений МВД // Вестник Бурятского государственного университета. 2011. №5. С.172-178.

5. Гаврилова Е.А. Вариабельность ритма сердца и спорт // Физиология человека. 2016. Т. 42, № 5. С. 121-129. https://doi.org/10.7868/S0131164616050088

6. Ковригина И.С. Социально-психологическая адаптация: сущность, виды и стадии формирования // Актуальные проблемы гуманитарных и естественных наук. 2009. № 9. С. 201-207.

7. Мальченкова В.В., Мальченков Е.В. Особенности профессиональной адаптации сотрудников полиции к профессиональной деятельности // Актуальные проблемы борьбы с преступлениями и иными правонарушениями. 2017. № 17-2. С. 160-163.

8. Михайлов В.М. Вариабельность ритма сердца (новый взгляд на старую парадигму). Иваново: ООО Нейрософт, 2017. 516 с.

9. Нежкина Л.Ю., Ярославцева И.В. Личностные и деловые качества сотрудников органов внутренних дел как факторы профессиональной адаптации // Вестник Санкт-Петербургского университета МВД России. 2016. №3 (71). C. 72-77.

10. Прокопенко Н.А. Влияние индивидуальных особенностей личности на вариабельность ритма сердца у женщин разного возраста при эмоциональном воздействии // Успехи геронтологии. 2011. Т. 24, № 3. С. 498-504.

11. Степанова О.Н. Мотивационный компонент в структуре профессиональной адаптации сотрудников УИС // Вестник Бурятского государственного университета. 2011. №5. С.168-172. 
12. Фетискин Н.П., Козлов В.В., Мануйлов Г.М. Социально-психологическая диагностика развития личности и малых групп. М.: Изд-во Института психотерапии, 2002. С.193-197.

13. Чугайнова О.Г. Проблемы профессиональной адаптации молодых специалистов // Наука в современном мире: теория и практика. 2015. № 1 (3). С. 46-52.

14. Arble E., Daugherty A.M., Arnetz B.B. Models of first responder coping: Police officers as a unique population // Stress Health. 2018. Vol. 34, No 5. P. 612-621. https://doi.org/10.1002/smi.2821

15. Hartley T.A., Violanti J.M., Mnatsakanova A., Andrew M.E., Burchfiel C.M. Military experience and levels of stress and coping in police officers // Int J Emerg Ment Health. 2013. Vol. 15, No 4. P. 229-39.

16. Nevels T.L., Burch J.B., Wirth M.D., Ginsberg J.P., McLain A.C., Andrew M.E., Allison P., Fekedulegn D., Violanti J.M. Shift Work Adaptation Among Police Officers: The BCOPS Study // Chronobiol Int. 2021. Vol. 30. P. 1-17. https:// doi.org/10.1080/07420528.2021.1895824

17. Sherwood L., Hegarty S., Vallières F., Hyland P., Murphy J., Fitzgerald G., Reid T. Identifying the Key Risk Factors for Adverse Psychological Outcomes Among Police Officers: A Systematic Literature Review // J Trauma Stress. 2019. Vol. 32, No 5. P. 688-700. https://doi.org/10.1002/jts.22431

18. Strahler J., Ziegert T. Psychobiological stress response to a simulated school shooting in police officers // Psychoneuroendocrinology. 2015. Vol. 51. P. 8091. https://doi.org/10.1016/j.psyneuen.2014.09.016

19. Schilling R., Herrmann C., Ludyga S., Colledge F., Brand S., Pühse U., Gerber M. Does Cardiorespiratory Fitness Buffer Stress Reactivity and Stress Recovery in Police Officers? A Real-Life Study // Front Psychiatry. 2020, Vol. 11. P. 594. https://doi.org/10.3389/fpsyt.2020.00594

20. Thayer J.F., Hansen A.L., Saus-Rose E., Johnsen B.H. Heart rate variability, prefrontal neural function, and cognitive performance: the neurovisceral integration perspective on self-regulation, adaptation, and health // Ann Behav Med. 2009. Vol. 37. No 2. P. 141-153. https://doi.org/10.1007/s12160-0099101-z

\section{References}

1. Baevskiy R.M., Ivanov G.G., Chireykin L.V. et al. Vestnik aritmologii, 2001, no. 24, pp. 65-86. http://www.vestar.ru/atts/1267/24baevsky.pdf

2. Bocharskaya I.A. Professional'naya i sotsial'no-psikhologicheskaya adaptatsiya studentov v vuze kak protsess vospitaniya sotsial'no-orientirovannoy i 
konkurentnosposobnoy lichnosti [Professional and socio-psychological adaptation of students at a university as a process of upbringing a socially-oriented and competitive personality]. Vestnik Kazanskogo gosudarstvennogo universiteta kul'tury $i$ iskusstv, 2006, no. 3, pp. 125-127.

3. Variabel'nost' serdechnogo ritma. Standarty izmereniya, fiziologicheskoy interpretatsii i klinicheskogo ispol'zovaniya / Rabochaya gruppa Evropeyskogo kardiologicheskogo obshchestva i Severo-Amerikanskogo obshchestv stimulyatsii i elektrofiziologii [Heart rate variability. Standards for Measurement, Physiological Interpretation and Clinical Use / Working Group of the European Society of Cardiology and the North American Societies of Stimulation and Electrophysiology]. Vestnik aritmologii, 1999, no. 11, pp. 53-78. http://www.vestar. ru/atts/2581/258101.pdf

4. Vasil'eva I.A. Osobennosti sotsial'no-psikhologicheskoy adaptatsii sotrudnikov spetspodrazdeleniy MVD [Features of social and psychological adaptation of employees of special forces of the Ministry of Internal Affairs]. Vestnik Buryatskogo gosudarstvennogo universiteta, 2011, no. 5, pp. 172-178.

5. Gavrilova E.A. Variabel'nost' ritma serdtsa i sport [Heart rate variability and sport]. Fiziologiya cheloveka, 2016, vol. 42, no. 5, pp. 121-129. https://doi. org/10.7868/S0131164616050088

6. Kovrigina I.S. Sotsial'no-psikhologicheskaya adaptatsiya: sushchnost', vidy i stadii formirovaniya [Socio-psychological adaptation: essence, types and stages of formation]. Aktual'nye problemy gumanitarnykh i estestvennykh nauk, 2009, no. 9, pp. 201-207.

7. Mal'chenkova V.V., Mal'chenkov E.V. Osobennosti professional'noy adaptatsii sotrudnikov politsii k professional'noy deyatel'nosti [Features of professional adaptation of police officers to professional activities]. Aktual'nye problemy bor'by s prestupleniyami i inymi pravonarusheniyami, 2017, no. 17-2, pp. 160-163.

8. Mikhaylov V.M. Variabel'nost' ritma serdtsa (novyy vzglyad na staruyu paradigmu) [Heart rate variability (a new look at the old paradigm)]. Ivanovo: Neurosoft, 2017, $516 \mathrm{p}$.

9. Nezhkina L.Yu., Yaroslavtseva I.V. Lichnostnye i delovye kachestva sotrudnikov organov vnutrennikh del kak faktory professional'noy adaptatsii [Personal and business qualities of employees of internal affairs bodies as factors of professional adaptation]. Vestnik Sankt-Peterburgskogo universiteta MVD Rossii, 2016, no. 3 (71), pp. 72-77.

10. Prokopenko N.A. Vliyanie individual'nykh osobennostey lichnosti na variabel'nost' ritma serdtsa u zhenshchin raznogo vozrasta pri emotsional'nom vozdeystvii [Influence of individual personality traits on heart rate variability in 
women of different ages with emotional impact]. Uspekhi gerontologii, 2011, vol. 24 , no. 3, pp. 498-504.

11. Stepanova O.N. Motivatsionnyy komponent v strukture professional'noy adaptatsii sotrudnikov UIS [Motivational component in the structure of professional adaptation of UIS employees]. Vestnik Buryatskogo gosudarstvennogo universiteta, 2011, no. 5, pp. 168-172.

12. Fetiskin N.P., Kozlov V.V., Manuylov G.M. Sotsial'no-psikhologicheskaya diagnostika razvitiya lichnosti i malykh grupp [Socio-psychological diagnostics of the development of personality and small groups]. M.: Institute of Psychotherapy Publ., 2002, pp. 193-197.

13. Chugaynova O.G. Problemy professional'noy adaptatsii molodykh spetsialistov [Problems of professional adaptation of young specialists]. Nauka $v$ sovremennom mire: teoriya i praktika, 2015, no. 1 (3), pp. 46-52.

14. Arble E., Daugherty A.M., Arnetz B.B. Models of first responder coping: Police officers as a unique population. Stress Health, 2018, vol. 34, no. 5, pp. 612-621. https://doi.org/10.1002/smi.2821

15. Hartley T.A., Violanti J.M., Mnatsakanova A., Andrew M.E., Burchfiel C.M. Military experience and levels of stress and coping in police officers. Int J Emerg Ment Health, 2013, vol. 15, no. 4, pp. 229-39.

16. Nevels T.L., Burch J.B., Wirth M.D., Ginsberg J.P., McLain A.C., Andrew M.E., Allison P., Fekedulegn D., Violanti J.M. Shift Work Adaptation Among Police Officers: The BCOPS Study. Chronobiol Int., 2021, vol. 30, pp. 1-17. https:// doi.org/10.1080/07420528.2021.1895824

17. Sherwood L., Hegarty S., Vallières F., Hyland P., Murphy J., Fitzgerald G., Reid T. Identifying the Key Risk Factors for Adverse Psychological Outcomes Among Police Officers: A Systematic Literature Review. J Trauma Stress, 2019, vol. 32, no. 5, pp. 688-700. https://doi.org/10.1002/jts.22431

18. Strahler J., Ziegert T. Psychobiological stress response to a simulated school shooting in police officers. Psychoneuroendocrinology, 2015, vol. 51, pp. 8091. https://doi.org/10.1016/j.psyneuen.2014.09.016

19. Schilling R., Herrmann C., Ludyga S., Colledge F., Brand S., Pühse U., Gerber M. Does Cardiorespiratory Fitness Buffer Stress Reactivity and Stress Recovery in Police Officers? A Real-Life Study. Front Psychiatry, 2020, vol. 11, pp. 594. https://doi.org/10.3389/fpsyt.2020.00594

20. Thayer J.F., Hansen A.L., Saus-Rose E., Johnsen B.H. Heart rate variability, prefrontal neural function, and cognitive performance: the neurovisceral integration perspective on self-regulation, adaptation, and health. Ann Behav Med., 2009, vol. 37, no. 2, pp. 141-153. https://doi.org/10.1007/s12160-009-9101-z 


\section{ДАННЫЕ ОБ АВТОРАХ}

Дерягина Лариса Евгеньевна, д-р мед. наук, профессор, профессор кафедры психологии Федеральное государственное казенное образовательное учреждение выстего профессионального образования Московский университет Министерства внутренних дел Российской Федерации имени В.Я. Кикотя ул. Академика Волгина, 12, г. Москва, 117437, Российская Федераџия lderyagina@mail.ru

Булатецкий Сергей Владиславович, д-р мед. наук, профессор, профессор кафедры патофизиологии Государственное бюджетное образовательное учреждение высшего профессионального образования Рязанский государственный медииинский университет имени академика И.П. Павлова ул. Высоковольтная, 9, г. Рязань, 390026, Российская Федераџия dr_bsv@mail.ru

\section{DATA ABOUT THE AUTHORS}

Larissa E. Deryagina, Dr. Sc. (Medicine), Professor, Professor of the Department of Psychology

Kikot Moscow University of the Ministry of the Interior of Russia 12, Academician Volgin Str., Moscow, 117437, Russian Federation lderyagina@mail.ru

SPIN-code: 6606-6628

ORCID: 0000-0001-5522-5950

ResearcherID: $N$ - 5766-2015

Sergey V. Bulatetskiy, Dr. Sc. (Medicine), Associate Professor, Professor of the Department of Pathophysiology Ryazan State Medical University

9, Vysokovoltnaja Str., Ryazan, 390026, Russian Federation dr_bsv@mail.ru SPIN-code: 2756-9179 ORCID: 0000-0002-6023-7523 ResearcherID: S-1631-2016 